\title{
Integrated Electro-Hydraulic Machine with Self-Cooling Possibilities for Non-Road Mobile Machinery
}

\author{
Pavel Ponomarev 1 - Tatiana Minav² - Rafael $\AA^{2} \operatorname{man}^{3}$ - Lauri Luostarinen ${ }^{3}$ \\ ${ }^{1}$ Lappeenranta University of Technology, LUT Energy, Finland \\ 2 Aalto University, School of Engineering, Finland \\ ${ }^{3}$ Lappeenranta University of Technology, LUT Mechanical Engineering, Finland
}

Over the past few years, due to the introduction of Tier 4 emission legislations, new developments for non-road mobile machinery (NRMM) applications to meet these stringent targets have been introduced. This paper presents a design concept for self-cooling of integrated electrohydraulic machinery for NRMM application. The applicability of this concept is shown for an integrated electro-hydraulic energy converter (IEHEC). Two cooling schematics (passive and active) are proposed. In the passive cooling scheme the coolant flow is obtained from the case drain leakage flow of the hydraulic machine. In the active cooling scheme a boost pump can be used for providing optimal coolant flow. We show that in an NRMM environment such an IEHEC can be utilized using a passive cooling scheme.

Keywords: fluid power, energy recuperation, hybrid drivetrain, hydraulic leakage, losses, cooling, efficiency, thermal management, nonroad mobile machinery

Highlights

- Design concept for self-cooling in Non-road mobile machinery applications was introduced.

- Two cooling schematics are proposed for an integrated electro-hydraulic energy converter.

- Integrated electro-hydraulic energy converter can be utilized with a passive cooling scheme.

- $\quad$ The proposed self-cooling concept allows a decrease in the power consumption in NRMM applications.

\section{O INTRODUCTION}

Globally, energy efficiency is becoming an increasingly important topic in the world of nonroad mobile machines (NRMM) [1] and [2]. In order to be competitive on the market, a working machine producer should have energy efficient - hybrid or fully electric - products available for customers [3] and [4]. Electrification is one of the ways of creating more energy efficient NRMM [5]. The possibilities of utilizing electrical components in NRMM have generated wide interest in this research area [6] and [7]. However, in working hydraulics the actuators are supplied by fluid power transmission and cannot be replaced by electrical analogues due to the low power density of electrical components compared with hydraulic ones [3]. On the other hand, the conventional valve controlled fluid power systems are in many cases of poor efficiency. Thus there emerges a need for hydraulic actuators that can be directly driven (or pump-controlled) via electrical machines [8] and [9]. In addition, a suitable electrical machine is required to maintain full torque at zero speed to provide the required pressure level in hydraulic actuators. Maintaining full torque at low rotational speeds sets a demand for effective cooling. In [10] an integrated electro-hydraulic energy converter (IEHEC) was introduced. Fig. 1 illustrates a cross-sectional cut of the IEHEC.

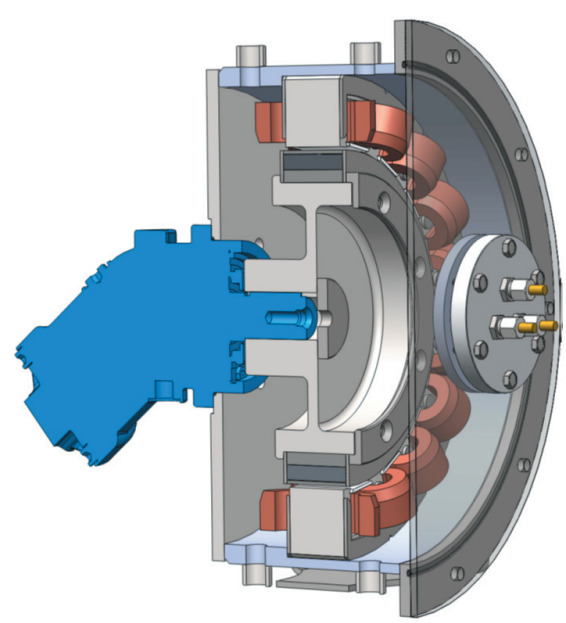

Fig. 1. Cross-sectional cut of the IEHEC [10]

A closed-loop fluid power circuit, which can replace traditional valve-controlled fluid power circuits in NRMM applications, consists of an IEHEC (hydraulic pump driven by an integrated electrical motor), flow compensation accessories and a hydraulic cylinder. The electrical machine is driven by a frequency converter with regenerative capabilities. 
The cooling of the integrated electrical machine is arranged by taking coolant flow from the fluid power system.

The hydraulic power can be obtained from the hydraulic machine driven by the integrated electrical machine. The electrical machine is controlled by a frequency converter connected to the main DC bus of an electrical/hybrid-electrical NRMM. Instead of a conventional directional control valve (DCV), an electrically drive pump-controlled fluid power system is applied, which offers the possibility of reducing both pipe line and throttling losses. The hydraulic machine driven by a controlled electrical machine delivers the exact amount of power required for the actuator. The amount of power is regulated electrically directly via a permanent magnet synchronous machine (PMSM) and a frequency converter. During lowering of payload in lifting applications from the initial extended position in NRMM, the control algorithm of the inverter allows the recuperation of excessive mechanical energy directly into electrical energy [3]. The released electrical energy can be stored in a battery or a super capacitor and reused later.

The efficiency of modern industrial electrical machines in the power range of 5 to $500 \mathrm{~kW}$ at nominal working point is typically 90 to $95 \%$. This means that about 5 to $10 \%$ of the input energy is converted to heat instead of producing effective work. Fig. 2 illustrates the measured efficiency chart of the electrical machine of an IEHEC [10].

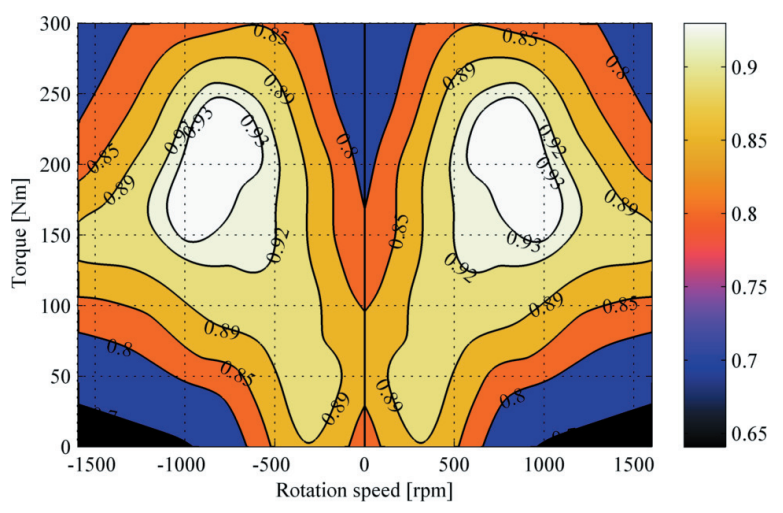

Fig. 2. Efficiency map of electrical machine

The high pressure level requires high torque from the electrical machine. High torque imposes high currents flowing into the machine windings. These high currents produce heat due to the Joule losses in the copper conductors. Additional heat is produced in the laminated iron stack due to the eddy-current and hysteresis losses in the iron [11]. If permanent magnets or solid conducting material are used in the machine construction, then eddy current losses are also generated in these components. This heat needs to be transferred from the electrical machine in order to limit the temperature rise and prevent possible damage to the winding insulation and permanent magnets [12]. Therefore, the cooling capability of electrical machines is an important factor in their operation. Usually, a separate cooling system is arranged for high-torque-density electrical machines, e.g. liquid cooling with a separate cooling pump or a fan system with a radiator assembly. Such a cooling system requires additional power to operate.

Many recent studies have focused on using oil as a cooling liquid [13] and [14]. Paper [15] presents comparisons of utilizing direct oil cooling approaches and conventional indirect cooling approaches for electrical motors mounted in hybrid electric vehicles or in zero emission vehicles.

In this paper two cooling approaches for electrical machines are introduced for non-road mobile machinery using the example of a direct-immersionliquid cooled electrical machine in the IEHEC. Firstly, the approach reduces the amount of additional power required for cooling purposes by utilization of case drain leakage in the hydraulic equipment under loading conditions. Secondly, the approach utilizes a controlled boost pump for maintaining an optimal thermal regime for the machinery. Only the first approach is analyzed in detail in order to ensure that passive cooling is capable of maintaining the machinery within its thermal limits.

The remainder of this paper is organized as follows. Section 1 suggests schemes and principles for the system cooling. Section 2 describes test setup and measurements performed for the passive cooling approach in detail. Section 3 shows the formulas that are used for thermal analysis of the system. Results of the analysis are described in Sections 4. Concluding remarks are presented in Section 5.

\section{COOLING METHODS CONFIGURATION}

This section describes the background, proposed schemes and principles for system cooling in NRMM applications.

\subsection{Leakage in Hydraulic Machines}

According to [16], the measured performance characteristics of a pump-motor are often supplied by the manufacturer in graphical form and are therefore typical for that type and size of hydraulic machine. Fig. 3 shows one way of presenting the performance 
characteristics of an axial piston machine acting as either a pump, or a motor. It can be seen that the optimum efficiency is located around a preferred pressure setting and speed. The optimum condition is dependent on the mechanical design and the machine size. It is important to ensure the best efficiency by selecting the correct machine size. The conditions for optimum efficiency are not the same when the machine role is reversed [16]. Efficiency charts of certain axial piston machine are presented in Fig. 3.

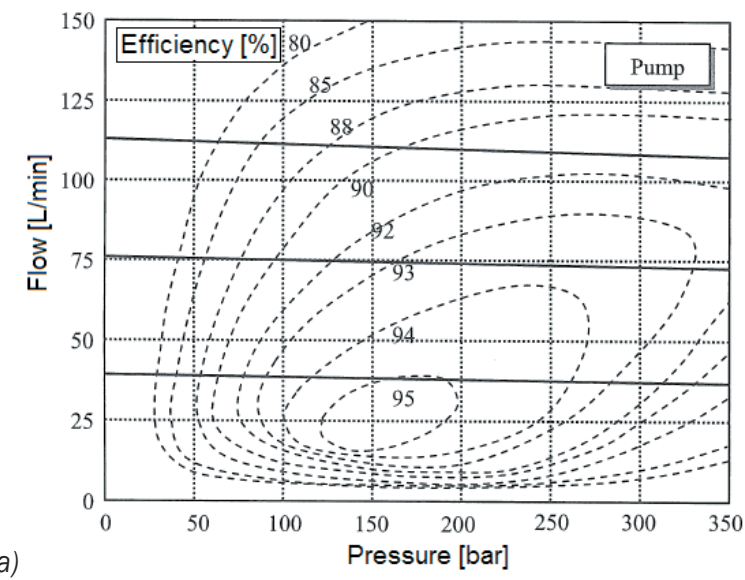

a)

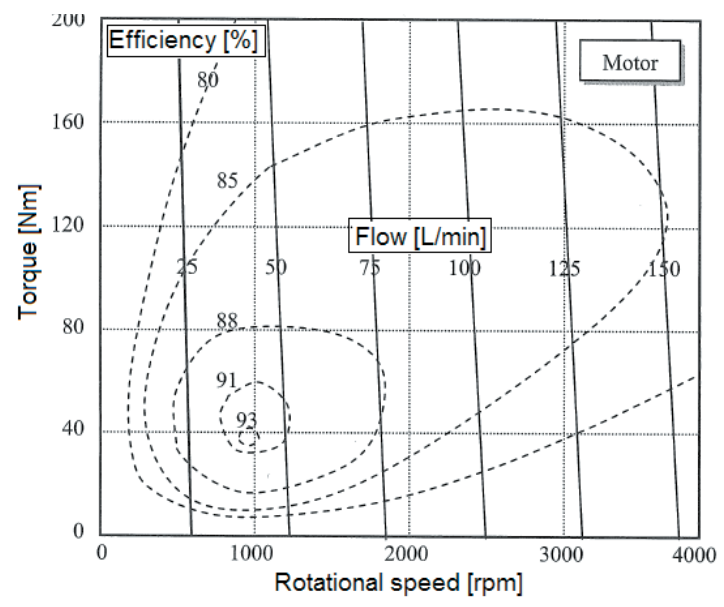

Fig. 3. Performance characteristics of an axial piston machine acting as: a) a pump and, b) a motor [16]

In Fig. $3 \mathrm{~b}$ torque corresponds to pressure and rotational speed to volume flow because the bentaxis piston hydraulic machine in question is of a fixed displacement type. This hydraulic machine can be operated in four quadrants.

According to [16], it is important to know that the difference between the input and the output flow rate is not the same as the case drain leakage (Fig 4). Pump internal leakage and resistance have a significant effect on the pump efficiency.
Therefore, it is difficult to predict case drain leakage at various operating points using just performance characteristics provided by the manufacturer. The exact leakage amount can be determined by extensive measurements where the number of measurement points is extremely large as case leakage depends on many variables, such as operating point (output pressure and flow rate), speed, inlet pressure, drain port pressure, temperature, and hydraulic oil properties.

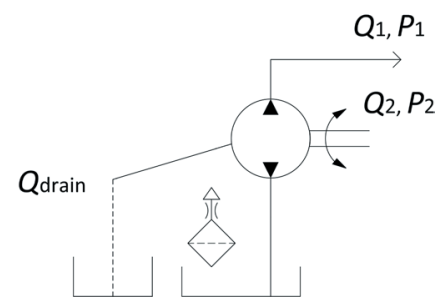

Fig. 4. Case drain leakage

Due to these practical difficulties, in this paper several assumptions concerning leakage flow rate are made in order to simplify analysis. According to the measurements, case drain leakage has been shown to be in the close vicinity of a certain value assumed to be constant and averaged from just a few measurement points.

\subsection{Active Cooling: Boost Pump Operation}

Usually, the case drain leakage flow in a closed-loop system is directed to the main hydraulic tank and is later returned to the circuit by a boosting pump. Fig. 5 illustrates a fluid power circuit with implemented active cooling.

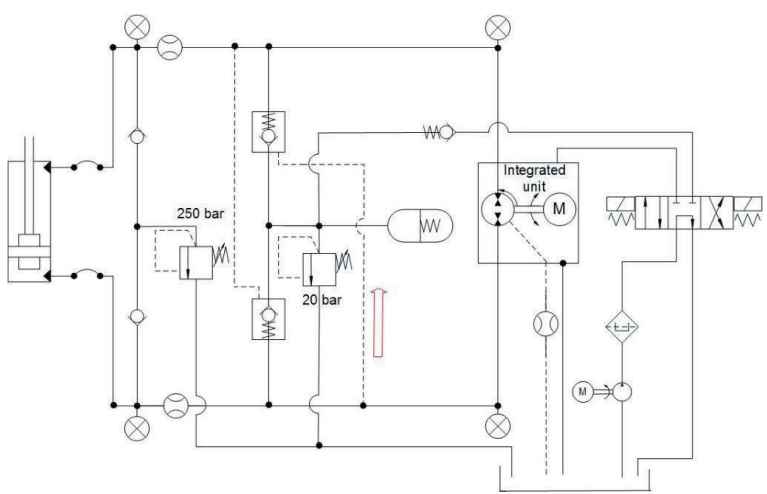

Fig. 5. Active cooling of an electrical machine with boost pump operation

The directional control valve is used for the prioritization of boost pump operation. The boost 
pump flow is primarily directed to the pressure accumulator; otherwise the flow is directed through the electrical machine to cool down the windings, according to the measured temperature. If no boost or cooling flow is required, the boost pump flow is directed to free flow in order to consume as low a power as possible. With more advanced control the boost pump could be switched off when neither boost nor cooling flow is required.

Pressure losses in electrical machines with boostpump cooling can be designed to be negligibly low by increasing the dimensions of the inlet and outlet lines. The dimension of the cooling lines does not influence the electro-mechanical operation of the electrical machine.

An active cooling scheme requires the following changes to the closed-loop fluid power circuit:

- directing boost pump flow (additional directional control valve),

- increased operation of the boost pump will increase energy consumption.

Therefore, an active cooling approach requires energy supply and additional components. Due to these technical limitations, passive self-cooling is suggested, as passive cooling does not require additional power for coolant circulation.

\subsection{Passive Self-Cooling}

Fig. 6 shows a simple closed-loop fluid power circuit with implemented passive self-cooling. Cooling flow is obtained from the case drain leakage flow of the hydraulic machine and it is then guided to integrated electrical machine. Pressure losses in the electrical machine can be seen as negligible since cooling of the stator stack does not require the housing to be filled to its top. The outgoing flow will move by gravity as long as the outlet and inlet ports are of adequate dimensions.

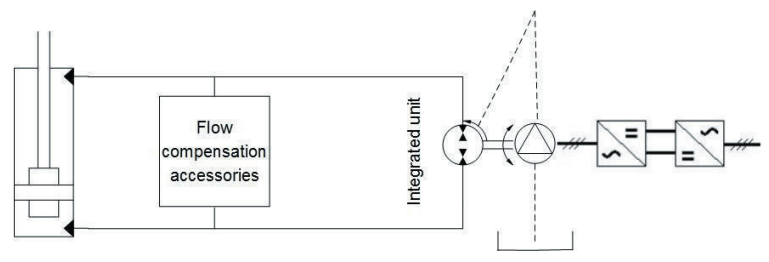

Fig. 6. Cooling of the electrical machine obtained from the case drain leakage flow

Due to the low flow rate of the case drain leakage it has been suggested to prefill the IEHEC and equip the drain line from the IEHEC to the tank with a throttle orifice and 2/2 directional control valve. By these means the heat produced in the windings can be effectively conducted into the IEHEC's metal body through the oil. In addition, the coolant flow rate, i.e. the case drain leakage flow, keeps bringing in the coolant oil. The directional control valve is there to prevent the IEHEC from draining to empty while standby.

The following Section 2 describes measurements of the case drain leakage flow. In these measurements the leakage flow was directed to the tank without guiding through the electrical machine.

\section{MEASUREMENT OF CASE DRAIN LEAKAGE FLOW}

Fig. 7 shows a photo of the case drain leakage measurement setup. The main component is the IEHEC [17]. The hydraulic machine maximum operating speed is $1500 \mathrm{rpm}$. The nominal pressure is $400 \mathrm{bar}$ and the nominal flow rate is $100 \mathrm{l} / \mathrm{min}$. An ABB ACSM1 drive was used to control the IEHEC. Fig. 5 shows the schematics of the hydraulic circuit implemented for testing case drain leakage flow.

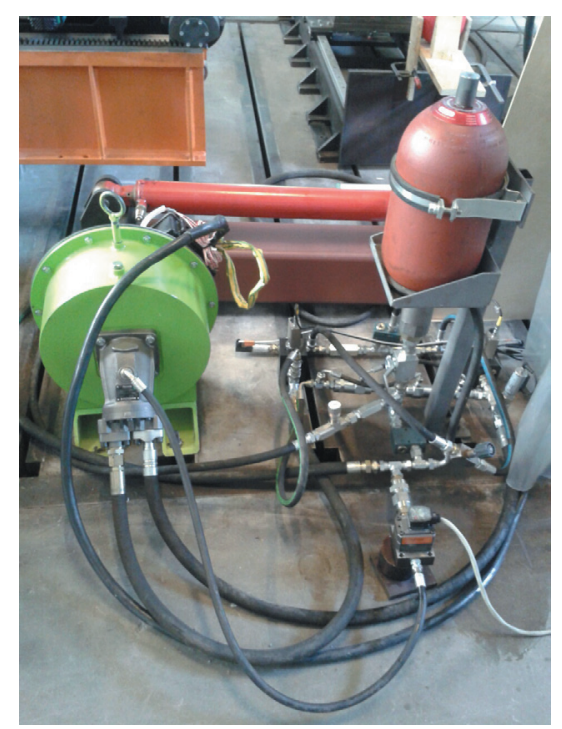

Fig. 7. Photo of test setup

Fig. 8 shows the leakage flow measurement points versus the rotational speed. The measurement was carried out by driving the fluid power circuit shown in Fig. 6 through its different operating points. During operation the drain leakage flow was measured using the flow sensor KRACHT VC 0.2 [19]. The leakage flow rate varies between 0.15 to $0.24 \mathrm{l} / \mathrm{min}$ during motoring mode, and between 0.19 to $0.33 \mathrm{l} /$ min in the generating mode of the electrical machine. Fig. 8 illustrates the different operational points during leakage measurements. Fluid temperature was 
maintained at $40{ }^{\circ} \mathrm{C}$. The positive speeds corresponds to the pumping mode for the hydraulic machine, and the negative rotational speeds to the motoring mode. The pressure level in bars is indicated as numbers near the measurement points. It can be seen in Fig. 8 that with increase of pressure drop (in bars) over the pump, leakage flow increased with the same rotational speed.

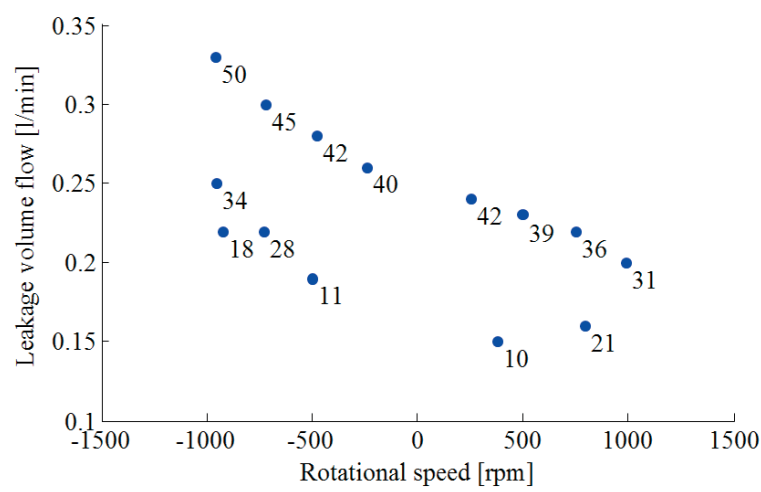

Fig. 8. Measurement points of case drain leakage flow versus rotational speed

The limitations of the measurement setup allowed measurements only in the low working pressure range below 50 bar. According to the measured points the case drain leakage flow in all other operating points is assumed to be $0.25 \mathrm{l} / \mathrm{min}$.

\section{THERMAL ANALYSIS}

Output power $P_{\text {out }}$ for an electrical machine at a motoring mode working point is calculated as:

$$
P_{\text {out }}=\frac{w \pi T}{60},
$$

where $w$ is motor speed, $T$ is torque.

Power losses $P_{\text {loss }}$ in an electrical machine at a motoring mode working point are calculated as follows:

$$
P_{\text {loss }}=\left(\frac{1}{\eta}-1\right) P_{\text {out }},
$$

where $\eta$ is the electrical machine efficiency. Fig. 9 shows the power losses that are converted to heat for the electrical machine in motoring mode obtained from the efficiency map of Fig. 2 utilizing Eqs. (1) and (2). The efficiency difference in permanent magnet electrical machines with direct torque control between motoring and generating modes is negligibly small.

Taking into account that at different operating points the electrical machine has different losses, it is clear that there are two regions - one where losses are below the cooling capability (the region where an electrical machine can be safely utilized) and another region where cooling capability is insufficient to compensate for power losses with constant coolant flow.

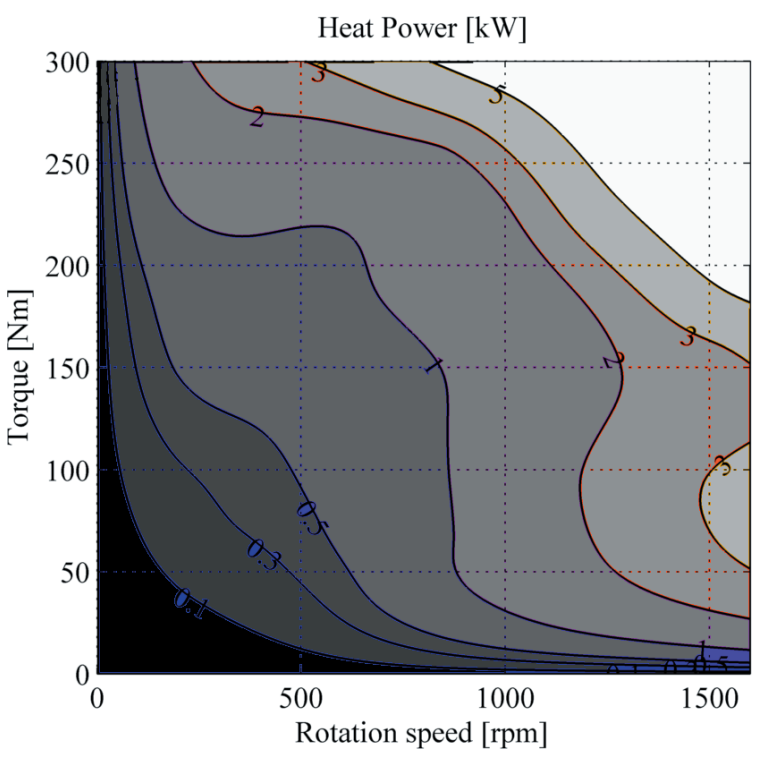

Fig. 9. Heat power due to losses in the electrical machine during motoring mode [10]

In this section the region of safe operation with self-cooling with case drain leakage flow is estimated. The following assumptions are used:

- Leakage flow is constant within the measured operating range (see Fig. 8) and is equal to 0.25 $\mathrm{L} / \mathrm{min}$.

- The whole amount of drain leakage oil participates in the heat removal. The possible flow of the coolant without capturing heat (e.g. directly from inlet to outlet without touching any hot surfaces) is neglected. Additionally, thermal resistance between the hot walls and the oil is neglected, and the thermal capacitance of the oil is also neglected by assuming ideal mixing [14].

- There is no other heat removal interface, no convection cooling or no heat removal by conduction, which represents a worst-case scenario.

- There is no heat transfer between the hydraulic machine and the electrical machine.

The thermal balance equation allows for estimation of thermal rise. The allowed thermal rise is calculated from the coolant inlet temperature and maximum allowable temperature for the electrical 
machine. The typical working temperature of hydraulic equipment is about $60{ }^{\circ} \mathrm{C}$. Therefore, the base temperature for thermal analysis is set to $60^{\circ} \mathrm{C}$. The maximum allowable temperature for the electrical machine is limited by mechanical constraints, winding insulation thermal rating, and thermal rating of PMs. For the IEHEC's electrical machine the maximum temperature is set to $130{ }^{\circ} \mathrm{C}$. Because the maximum operation temperature is higher than recommended for conventional mineral-oil-based hydraulic fluid, a fire-resistant hydraulic fluid (FRHF) should be used. According to [18], FRHF can be used continuously in the temperature range up to $150{ }^{\circ} \mathrm{C}$. Therefore, the allowable temperature rise is $\Delta T=130^{\circ} \mathrm{C}-60^{\circ} \mathrm{C}=$ $70{ }^{\circ} \mathrm{C}$.

The temperature rise at every operating point under the abovementioned assumptions can be calculated as:

$$
\Delta T=\frac{P_{\text {loss }}}{c_{\mathrm{p}} Q_{\text {leak }} \rho}
$$

where $c_{\mathrm{p}}$ is the specific heat and it is $2300 \mathrm{~J} / \mathrm{kgK} ; \rho$ is the oil density and is equal to $880 \mathrm{~kg} / \mathrm{m}^{3} ; Q_{\text {leak }}$ is the case drain leakage oil flow rate in $1 / \mathrm{min}$ and $P_{\text {loss }}$ is estimated from the efficiency map as shown in Fig. 9.

Using these equations an operating region can be estimated along the whole operating range of the IEHEC, where the temperature rise under the abovementioned assumptions is acceptable.

\section{RESULTS}

In this study, the target was to show the feasibility of the self-cooling concept of integrated electro-hydraulic machinery for hybrid/electric NRMM applications. The feasibility depends on the assumptions. A lower temperature difference $(\Delta \mathrm{T})$ and a lower case drain flow rate can reduce the allowed temperature region in a significant manner. Therefore, to ensure practicality of this approach, the IEHEC's case drain leakage flow should be measured on a matrix of operating points along the whole operating range.

Fig. 10 shows the theoretical allowed region (light) for the IEHEC, where a passive self- cooling scheme is acceptable under the abovementioned assumptions.

This allowed region of operation is valid for the particular studied IEHEC. With a change in efficiency, or leakage flow, or cooling media the region could vary.

According to Fig. 10, if the intended region of operation is located in the allowed region for self- cooling, the electro-hydraulic machinery can operate safely without using additional power for cooling purposes. Short-time operation outside the allowed region can be acceptable as the cooling media has quite a high thermal capacity. Excessive heat can be accumulated for a short time within the machine components and the cooling media, assuming that the IEHEC operation point will return as fast as possible to the allowable operating region.

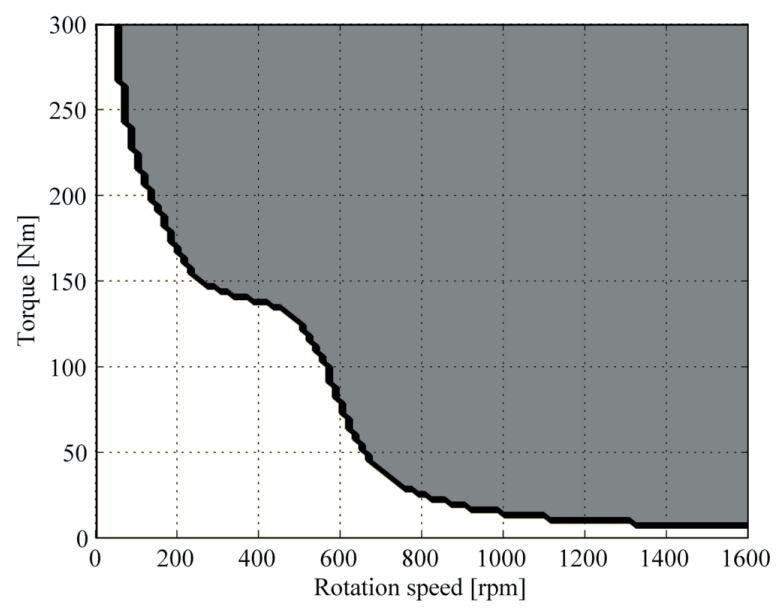

Fig. 10. Allowed region of operation of the IEHEC

This novel type of passive cooling would decrease the power consumption and increase the system efficiency in NRMM applications. An example of this application is a mobile crane lifting-lowering heavy payloads. In the case of active cooling, during the lifting cycle the main fluid power circuit reserves all the capacity of the boost pump and, therefore, it cannot be used in cooling. If the lifting cycle is longer it would require the addition of one more pump to cover the cooling needs. This would further increase the fuel consumption, the mass and the investment. Passive cooling is available even during a longer work cycle without additional power consumption and extra costs.

\section{CONCLUSIONS}

This paper introduces a new cooling method for high-torque-density electro-hydraulic machinery for NRMM applications. The self-cooling concept allows the reduction of additional components for cooling from the NRMM. The results show the allowed region for the IEHEC, where a passive self-cooling scheme is acceptable under the abovementioned assumptions. The proposed self-cooling concept allows a decrease 
in the power consumption and an increase in the system efficiency in NRMM applications.

\section{ACKNOWLEDGEMENTS}

The research introduced in this paper has been carried out as a part of the EFFIMA (Energy and Life Cycle Cost Efficient Machines) - program of FIMECC (Finnish Metals and Engineering Competence Cluster). The research was enabled by the financial support of ECV Tubridi project (Tekes, the Finnish Funding Agency for Technology and Innovation) Laboratory of Electric Drives (LUT Energy), Laboratory of Intelligent Machines (LUT Mechanical Engineering) at Lappeenranta University of Technology and the Department of Engineering Design and Production of the School of Engineering of Aalto University.

\section{REFERENCES}

[1] Heybroek, K. (2008). Saving Energy in Construction Machinery using Displacement Control Hydraulics: Concept Realization and Validation. Licentiate thesis, Linköpings University, Linköping.

[2] Ivantysynova, M. (2008). Innovations in pump design-what are future directions. International Symposium on Fluid Power, Toyama, D0l:10.5739/isfp.2008.59.

[3] Minav, T. (2011). Electric-Drive-Based Control and Electric Energy Regeneration in a Hydraulic System. PhD thesis, Acta Universitatis Lappeenrantaensis 436, Lappeenranta University of Technology, Lappeenranta.

[4] Immonen, P. (2013). Energy Efficiency of a Diesel-Electric Mobile Working Machine. PhD. thesis, Acta Universitatis Lappeenrantaensis 518, Lappeenranta University of Technology, Lappeenranta.

[5] Lin, T., Wang, Q., Hu, B., Gong, W., (2010). Development of hybrid powered hydraulic construction machinery. Journal Automation in Construction, vol. 19, no. 1, p. 11-19, DOI:10.1016/j.autcon.2009.09.005.

[6] Ming, X., Bo, J., Guojin, C., Jing, N. (2013). Speed-control of energy regulation based variable-speed electrohydraulic drive. Strojniški vestnik - Journal of Mechanical Engineering, vol. 59, no. 7-8, p. 433-442, D0l:10.5545/sv-jme.2012.911.

[7] Minav, T., Sinkkonen, A., Hänninen, H., Laurila, L., Pyrhönen, J. (2014). Energy recovery system comparison of reach truck. Strojniški vestnik - Journal of Mechanical Engineering, vol. 60, no. 4, p. 232-240, DOl:10.5545/sv-jme.2013.1581.
[8] Andersen, T., Hansen, M., Pedersen, H. (2005). Regeneration of Potential Energy in Hydraulic Forklift Trucks. Proceedings of the $6^{\text {th }}$ International Conference on Fluid Power Transmission and Control.

[9] Minav, T., Laurila L., Pyrhönen J., Vtorov V.,(2011). Direct pump control effects on the energy efficiency in an electro-hydraulic lifting system. Journal International Review of Automatic Control, vol. 4, no. 2, p. 235-242.

[10] Ponomarev, P. (2013). Tooth-Coil Permanent Magnet Synchronous Machine Design for Special Applications. $\mathrm{PhD}$ thesis, Acta Universitatis Lappeenrantaensis 531, Lappeenranta University of Technology, Lappeenranta.

[11] Yamazaki, K., Fukushima, N. (2010). Iron-loss modeling for rotating machines: comparison between Bertotti's three-term expression and 3-D eddy-current analysis. IEEE Transactions on Magnetics, vol. 46, no. 8, p. 3121-3124, Dol:10.1109/ TMAG.2010.2044384.

[12] Smeets, J.P.C., Soulard, J., Lomonova, E.A., (2010). Thermal analysis of a winding turn-to-turn fault in PM synchronous machine. XIX International Conference on Electrical Machines, Rome, p. 1-6, D0I:10.1109/ICELMACH.2010.5608010.

[13] Sim, J.H. Chai, S.H., Kim, D.M., Hong, J.P. (2013). Temperature prediction of oil-cooled IPMSM for in-wheel direct-drive through lumped parameter thermal model. International Conference on Electrical Machines and Systems, Busan, p. 134-138, DOI:10.1109/ICEMS.2013.6754540.

[14] Ponomarev, P., Polikarpova, M., Pyrhonen, J. (2012). Conjugated fluid-solid heat transfer modeling of a directly-oilcooled PMSM using CFD. International Symposium on Power Electronics, Electrical Drives, Automation and Motion, p. 141145, DOI:10.1109/SPEEDAM.2012.6264385.

[15] Huang, Z., Nategh, S., Alakula, M., Lassila, V., Yuan, J. (2012) Direct Oil Cooling of Traction Motors in Hybrid Drives. IEEE International Conference Electric Vehicle, Greenville, p. 1-8, DOI:10.1109/IEVC.2012.6183163.

[16] Watton, J. (2009). Fundamentals of Fluid Power Control, Cambridge University Press, Cambridge, D0l:10.1017/ Св09781139175241.

[17] Ponomarev, P., Åman, R., Handroos, H., Immonen, P., Pyrhonen, J., Laurila, L. (2014). High power density integrated electro-hydraulic energy converter for heavy hybrid off-highway working vehicles. IET Electrical Systems in Transportation, vol. 4, no. 4, p. 114-121, Dol:10.1049/iet-est.2013.0009.

[18] Exxon Mobil Corporation (2014). Mobil Pyrotec HFD 46 FireResistant Hydraulic Fluid, from: http://www.mobil.com/USAEnglish/Lubes/PDS/GLXXENINDMOMobil_Pyrotec_HFD_46. aspx, accessed on 2014-10-08.

[19] KRACHT GmbH. (2014). Gear Type Flow Meter VC, from http:// kracht.eu/uploads/tx_ttproducts/datasheet/VC_GB_0112_01.pdf, accessed on 2014-10-08. 